\title{
Updated Smithsonian Astrophysical Observatory Ozone Monitoring Instrument (SAO OMI) formaldehyde retrieval
}

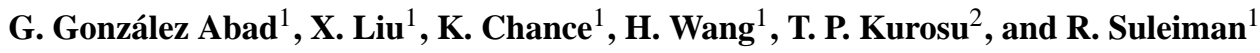 \\ ${ }^{1}$ Harvard-Smithsonian Center for Astrophysics, Cambridge, MA, USA \\ ${ }^{2}$ Jet Propulsion Laboratory, Pasadena, CA, USA \\ Correspondence to: G. González Abad (ggonzalezabad@cfa.harvard.edu)
}

Received: 29 November 2013 - Published in Atmos. Meas. Tech. Discuss.: 7 January 2014

Revised: 24 September 2014 - Accepted: 13 November 2014 - Published: 5 January 2015

\begin{abstract}
We present and discuss the Smithsonian Astrophysical Observatory $(\mathrm{SAO})$ formaldehyde $\left(\mathrm{H}_{2} \mathrm{CO}\right)$ retrieval algorithm for the Ozone Monitoring Instrument (OMI) which is the operational retrieval for NASA OMI $\mathrm{H}_{2} \mathrm{CO}$. The version of the algorithm described here includes relevant changes with respect to the operational one, including differences in the reference spectra for $\mathrm{H}_{2} \mathrm{CO}$, the fit of $\mathrm{O}_{2}-\mathrm{O}_{2}$ collisional complex, updates in the high-resolution solar reference spectrum, the use of a model reference sector over the remote Pacific Ocean to normalize the retrievals, an updated air mass factor (AMF) calculation scheme, and the inclusion of scattering weights and vertical $\mathrm{H}_{2} \mathrm{CO}$ profile in the level 2 products. The setup of the retrieval is discussed in detail. We compare the results of the updated retrieval with the results from the previous $\mathrm{SAO} \mathrm{H}_{2} \mathrm{CO}$ retrieval. The improvement in the slant column fit increases the temporal stability of the retrieval and slightly reduces the noise. The change in the AMF calculation has increased the AMFs by $20 \%$, mainly due to the consideration of the radiative cloud fraction. Typical values for retrieved vertical columns are between $4 \times 10^{15}$ and $4 \times 10^{16}$ molecules $\mathrm{cm}^{-2}$, with typical fitting uncertainties ranging between 45 and $100 \%$. In high-concentration regions the errors are usually reduced to $30 \%$. The detection limit is estimated at $1 \times 10^{16}$ molecules $\mathrm{cm}^{-2}$.
\end{abstract}

\section{Introduction}

$\mathrm{H}_{2} \mathrm{CO}$ is one of the most abundant hydrocarbons in the troposphere and a key constituent, despite its short lifetime of $1.5 \mathrm{~h}$, due to photolysis and oxidation by the hydroxyl radical (OH) (Anderson et al., 1996; Brune et al., 1999). Background levels of $\mathrm{H}_{2} \mathrm{CO}$ (concentrations below $1 \mathrm{ppbv}$ ) are sustained by the oxidation of methane, but over continental regions the oxidation of short-lived, non-methane volatile organic compounds (NMVOCs) from anthropogenic, biogenic, and pyrogenic origins and direct emissions from fires and industrial activities can produce enhanced concentrations of $\mathrm{H}_{2} \mathrm{CO}$ within the boundary layer of over 5 ppbv (Houweling et al., 1998; Kanakidou et al., 2005; Lowe and Schmidt, 1983; Parrish et al., 2012). Given its short lifetime, measurements of $\mathrm{H}_{2} \mathrm{CO}$ from satellites can be used as a proxy for NMVOC emissions and can be used to estimate top-down emission inventories (Barkley et al., 2008; Fu et al., 2007; Marais et al., 2012; Stavrakou et al., 2009a, b).

Ground-based measurements of $\mathrm{H}_{2} \mathrm{CO}$ total columns in the ultraviolet (UV) and infrared spectral ranges are well established in the scientific community. For example, over Lauder station in New Zealand, the mean column reported by Jones et al. (2009) using high-resolution Fourier-transform infrared spectroscopy is $4.9 \times 10^{15}$ molecules $\mathrm{cm}^{-2}$. The same technique was used by Vigouroux et al. (2009) to measure $\mathrm{H}_{2} \mathrm{CO}$ over Réunion Island in the Indian Ocean. They also used the multi-axis differential optical absorption spectroscopy (MAX-DOAS) technique, obtaining good agreement between the two techniques with concentrations around $4.0 \times 10^{15}$ molecules $\mathrm{cm}^{-2}$. MAX-DOAS $\mathrm{H}_{2} \mathrm{CO}$ measurements (Heckel et al., 2005; Peters et al., 2012; Wagner et al., 2011; Pinardi et al., 2013) will be of great value in validating our $\mathrm{H}_{2} \mathrm{CO}$ measurements.

$\mathrm{H}_{2} \mathrm{CO}$ has been measured from space using both UV and the infrared radiation. Infrared solar occultation measurements from the Atmospheric Chemistry ExperimentFourier Transform Spectrometer (ACE-FTS) (Dufour et al., 
2009) and emission measurements from the Michelson Interferometer for Passive Atmospheric Sounding (MIPAS) (Steck et al., 2008) are able to measure $\mathrm{H}_{2} \mathrm{CO}$ profiles from the stratosphere to the upper troposphere. UV nadir measurements from the Global Ozone Monitoring Experiment (GOME), GOME-2, the SCanning Imaging Absorption spectrometer for Atmospheric CHartographY (SCIAMACHY), and Ozone Monitoring Instrument (OMI) have all been used to retrieve $\mathrm{H}_{2} \mathrm{CO}$ vertical columns from space (Chance et al., 2000; Palmer et al., 2001; Kurosu et al., 2004; Wittrock et al., 2006; De Smedt et al., 2008, 2012; Vrekoussis et al., 2010).

We consider the update of the operational Smithsonian Astrophysical Observatory (SAO) $\mathrm{H}_{2} \mathrm{CO}$ retrieval necessary. Since 2009 there has been a significant increase of the retrieved background $\mathrm{H}_{2} \mathrm{CO}$ values - e.g., Kim et al. (2011) with data becoming noisier with time. There are new reference spectra available that need to be updated. We are also including for the first time scattering weight information in the level 2 files. We describe the theoretical basis of the SAO OMI $\mathrm{H}_{2} \mathrm{CO}$ operational retrieval algorithm and the details of the setup we are using. This algorithm is used at SAO, with the necessary adjustments, for the retrieval of other trace gases ( $\mathrm{BrO}$ (Raid Suleiman, personal communication), $\mathrm{C}_{2} \mathrm{H}_{2} \mathrm{O}_{2}$ (Miller et al., 2014), $\mathrm{H}_{2} \mathrm{O}$ (Wang et al., 2014)) from OMI.

This paper first focuses on explaining the column retrievals by describing the OMI instrument characteristics, the spectral fitting, the conversion of slant column density (SCD) to vertical column density (VCD), and the reference sector normalization. It then compares previous $\mathrm{SAO} \mathrm{H}_{2} \mathrm{CO}$ retrievals with these new ones and, finally, summarizes this study.

\section{SAO OMI $\mathrm{H}_{2} \mathrm{CO}$ observations}

\subsection{The OMI instrument}

OMI (Levelt et al., 2006) was launched on 15 July 2004 onboard the NASA Earth Observing System (EOS) Aura platform into a Sun-synchronous polar orbit with an average altitude of $705 \mathrm{~km}$ and a period of $99 \mathrm{~min}$, giving 14.7 orbits per day. The Equator-crossing time is 13:42 in the ascending node. OMI measures UV/visible (UV/Vis) solar backscattered radiation using two-dimensional charge-coupled devices (CCDs) from 270 to $500 \mathrm{~nm}$ in three channels: UV-1 from 264 to $311 \mathrm{~nm}, \mathrm{UV}-2$ from 307 to $383 \mathrm{~nm}$, and Vis from 349 to $504 \mathrm{~nm}$, with spectral resolutions of $0.63,0.42$, and $0.63 \mathrm{~nm}$, respectively. We use UV-2 for $\mathrm{H}_{2} \mathrm{CO}$ retrievals. In nominal operation mode, the information in the across-track direction is binned by a factor of 8 , resulting in 60 binned ground pixels in the UV-2 channel. OMI has a cross-track field of view of $115^{\circ}$, resulting in a swath of $2600 \mathrm{~km}$, with pixel size between $13 \times 24 \mathrm{~km}^{2}$ at nadir and $26 \times 135 \mathrm{~km}^{2}$ at the swath edges, providing daily global coverage.

\subsection{SAO OMI $\mathrm{H}_{2} \mathrm{CO}$ retrieval}

We retrieve VCDs of $\mathrm{H}_{2} \mathrm{CO}$ using a two-step approach. First, we spectrally fit OMI radiances to retrieve SCDs using the basic optical differential spectroscopy (BOAS) method (Chance, 1998). Second, we convert the SCDs to VCDs using air mass factors (AMFs) calculated offline with a radiative transfer model. Finally, we apply post-processing corrections based on a reference sector over the remote Pacific Ocean (Khokhar et al., 2005).

\subsubsection{Spectral fitting}

SCDs of $\mathrm{H}_{2} \mathrm{CO}$ are determined by direct fitting of OMI radiances (Chance, 1998). First, irradiances and radiance wavelengths are calibrated using cross correlation with a highresolution solar spectrum (Caspar and Chance, 1997). We use the high-resolution solar spectrum recently published by Chance and Kurucz (2010). Two variables may be fitted in the wavelength calibration: spectral shift and squeeze. As they are highly correlated except for very wide fitting regions, we only fit the spectral shift. Wavelength-calibrated radiances are fitted to model spectra. The construction of the model spectra starts with the radiances from the remote $\mathrm{Pa}-$ cific Ocean, which substitute for the daily solar irradiance, scaled by a factor plus the contributions from the molecular ring correction (Chance and Spurr, 1997) and a correction accounting for the aliasing introduced from spectral undersampling computed online (Chance, 1998; Chance et al., 2005). To this term we apply the Beer-Lambert law to account for the molecular absorption from $\mathrm{O}_{3}$ (Malicet et al., 1995), $\mathrm{NO}_{2}$ (Vandaele et al., 1998), $\mathrm{BrO}$ (Wilmouth et al., 1999), the $\mathrm{O}_{2-}$ $\mathrm{O}_{2}$ collision complex (Thalman and Volkamer, 2013), and $\mathrm{H}_{2} \mathrm{CO}$ (Chance and Orphal, 2011), all convolved with the OMI slit function measured prior to launch (Dirksen et al., 2006). After accounting for the molecular absorption, we include the common mode spectrum obtained by averaging the fitting residuals for each orbit. We finish the construction of the model spectra by considering two low-order closure polynomials that help to account for low-frequency features of the measured radiance in the fitting window (Eq. 1).

$$
\begin{aligned}
I & =\left[\left(a I_{0}+\sum_{i} \alpha_{i} X_{i}\right) e^{-\sum_{j} \alpha_{j} X_{j}}+\sum_{k} \alpha_{k} X_{k}\right] \sum_{n} \alpha_{n} X_{n} \\
& +\sum_{m} \alpha_{m} X_{m}
\end{aligned}
$$

In Eq. (1), $a$ is the factor applied to $I_{0}$, the solar irradiance, or in this case the radiance reference from the remote $\mathrm{Pa}$ cific Ocean; $\alpha_{i} X_{i}$ are terms added before the trace gas contributions, including the ring spectrum and the undersampling correction; $\alpha_{j} X_{j}$ are the Beer-Lambert law contributions from the trace gases; $\alpha_{k} X_{k}$ are the terms added afterwards, which in this particular case is the common mode spectrum; and $\alpha_{n} X_{n}$ and $\alpha_{m} X_{m}$ are the scaling and baseline 

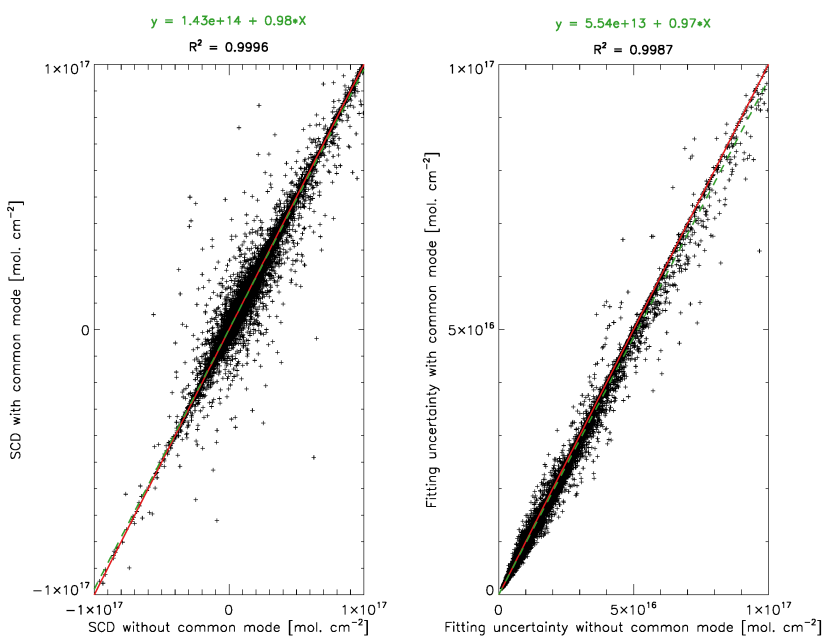

Figure 1. Fitting results of $\mathrm{H}_{2} \mathrm{CO}$ SCDs for OMI Orbit 11118 with and without common mode (17 August 2006 overpass over South America).

closure polynomials. The inclusion of the common mode has the intention of reducing the fitting residuals without affecting the values of the retrieved slant columns since its correlation with the $\mathrm{H}_{2} \mathrm{CO}$ cross sections is small. Figure 1 shows the scatterplots of the SCDs and the fitting uncertainties for Orbit 11118 comparing the retrieval when we use or do not use the common mode. The correlation values between the two setups is high $(0.9996$ for the SCDs and 0.9987 for the fitting uncertainties), with small changes in the SCD values. As said before, the main reason to include the common mode is to reduce the root mean square (rms) and therefore the fitting uncertainties, which, as shown in the right panel of Fig. 1, are reduced on average $2 \%$.

Figure 2 shows the correlations of the other molecules included in the fitting with $\mathrm{H}_{2} \mathrm{CO}$ for Orbit 8537 . We are also showing the correlation with the common mode. Correlations of $\mathrm{H}_{2} \mathrm{CO}$ with $\mathrm{O}_{3}$ (at 228 and $295 \mathrm{~K}$ ), with $\mathrm{NO}_{2}, \mathrm{O}_{2}-\mathrm{O}_{2}$ collision complex, and the common mode spectrum are all small. The orbit-averaged correlations are $0.15,0.15,0.13$, 0.05 , and 0.01 , respectively. The common mode is weakly correlated with $\mathrm{H}_{2} \mathrm{CO}$. As expected from the correlation of cross sections between $\mathrm{BrO}$ and $\mathrm{H}_{2} \mathrm{CO}$, the correlation of the retrieved column amount between them is strong. The average correlation coefficient for the whole orbit is 0.44 . As a result, $\mathrm{H}_{2} \mathrm{CO}$ retrieval is affected if $\mathrm{BrO}$ is present in significant amounts in the atmosphere.

Instead of using the traditional solar irradiance as $I_{0}$ in Eq. (1), we use radiances over the remote Pacific Ocean obtained from an orbit as close to $165^{\circ} \mathrm{W}$ as possible, measured within $24 \mathrm{~h}$ of the orbit to be processed. We build the radiance reference by averaging the radiance spectra over the Pacific between $30^{\circ} \mathrm{S}$ and $30^{\circ} \mathrm{N}$. Then we use this radiance reference as $I_{0}$. Due to the weak absorption of $\mathrm{H}_{2} \mathrm{CO}$, the use of the radiance reference over the Pacific helps to address some

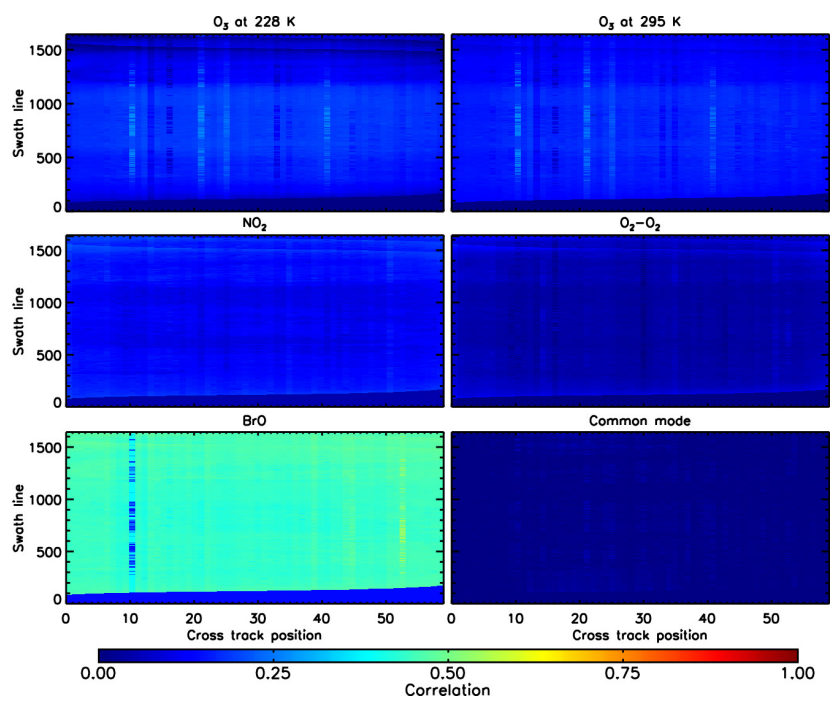

Figure 2. Correlations of $\mathrm{H}_{2} \mathrm{CO}$ with the rest of molecules considered in the spectral fitting and the common mode spectrum for Orbit 8537 (21 February 2006 overpass over Africa and Europe).

instrument issues observed in previous versions of the $\mathrm{H}_{2} \mathrm{CO}$ retrieval, including the well-known striping problems of OMI (Veihelmann and Kleipool, 2006). The characteristics of the spectral fit, reference spectra, closure polynomials, and online computed corrections are summarized in Table 1 . The SCD that minimizes the cost function $\chi^{2}$ calculated from the difference between the measured and modeled radiance is retrieved using a nonlinear least-squares inversion method implemented in the ELSUNC software (Lindström and Wedin, 1988).

We have also implemented an iterative approach to remove pixels with outliers in the fitting residual. After performing an initial fit of the SCD, we check the value of the residuals for each spectral point. If the residual for a spectral pixel is outside $3 \sigma$ of the mean fitting residual, then this point is rejected and the retrieval is performed again. This process is repeated for a maximum of two times. With this approach we can minimize the effect of the South Atlantic anomaly and keep the stability of the retrieval along the mission. This method has been used as well in GOME- $2 \mathrm{NO}_{2}$ retrievals (Richter et al., 2011).

We use a fitting window from 328.5 to $356.5 \mathrm{~nm}$, similar to other windows reported in the literature for GOME, GOME2, and SCIAMACHY (De Smedt et al., 2008, 2012). It is a minor change compared with our previous fitting window, 327.5 to $356.5 \mathrm{~nm}$, but its use coupled with the effects of the updates in the cross sections, the inclusion of the $\mathrm{O}_{2}-\mathrm{O}_{2}$ collision complex, and the iterative exclusion of spectral pixels with big fitting residuals helps to keep the fitting of SCDs stable over time, minimizing the effects of instrument degradation. We will further extend the analysis on the effect of each one of these changes in Sect. 3, where we compare the previous and the new $\mathrm{H}_{2} \mathrm{CO} \mathrm{SAO}$ product, the latter of which 
Table 1. Fitting window and parameters for deriving $\mathrm{H}_{2} \mathrm{CO}$ slant column density.

\begin{tabular}{ll}
\hline Fitting window & $328.5-356.5 \mathrm{~nm}$ \\
Radiance reference spectrum & Computed online over the remote Pacific Ocean between \\
& $30^{\circ} \mathrm{N}$ and $30^{\circ} \mathrm{S}$ \\
Baseline polynomial & 3 rd order \\
Scaling polynomial & 3 rd order \\
Instrument slit function & Hyper-parameterization of pre-flight measurements \\
& Dirksen et al. (2006) \\
$\mathrm{Solar}$ reference spectrum & Chance and Kurucz (2010) \\
$\mathrm{H}_{2} \mathrm{CO}$ cross sections & Chance and Orphal (2011), 300 K \\
$\mathrm{O}_{3}$ cross sections & Malicet et al. (1995), 228 and 295 K \\
$\mathrm{NO}_{2}$ cross sections & Vandaele et al. (1998), 220 K \\
$\mathrm{BrO}$ cross sections & Wilmouth et al. (1999), 228 K \\
$\mathrm{O}_{2}-\mathrm{O}_{2}$ collision complex cross sections & Thalman and Volkamer (2013), 293 K \\
Molecular ring cross sections & Chance and Spurr (1997) \\
Undersampling correction & Computed online Chance et al. (2005) \\
Residual common mode spectrum & Computed online between 30 N and $30^{\circ} \mathrm{S}$ \\
\hline
\end{tabular}
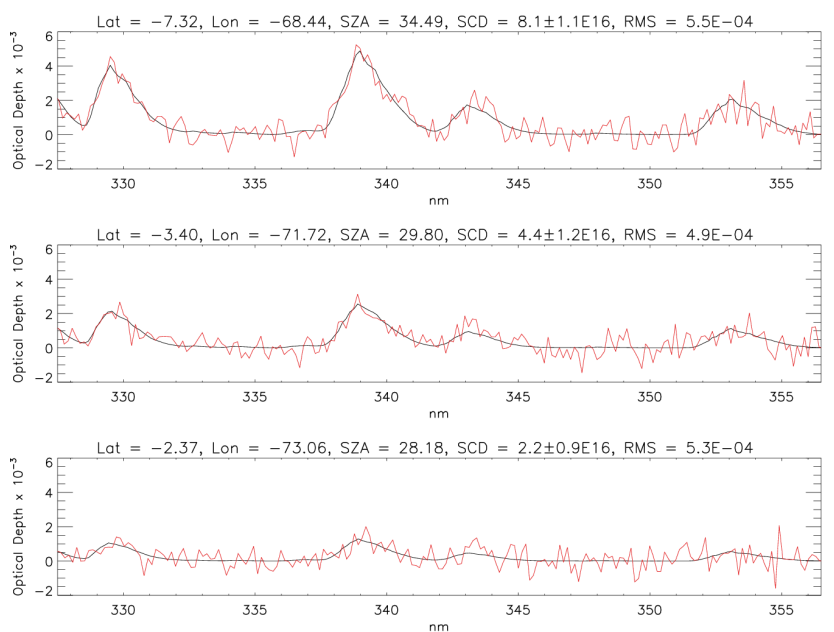

Figure 3. Fitting of $\mathrm{H}_{2} \mathrm{CO}$ in OMI Orbit 11118 (17 August 2006 overpass over South America) for high (top), medium (middle), and low (bottom) amounts. The black line is the fitted $\mathrm{H}_{2} \mathrm{CO}$ optical depth, and the red line is the fitted $\mathrm{H}_{2} \mathrm{CO}$ optical depth plus the fitting residuals.

is presented here. Figure 3 shows the residual and the results of the fitting for three pixels of Orbit 11118 (17 August 2006) over South America. The thick black line is the fitted $\mathrm{H}_{2} \mathrm{CO}$ optical depth, and the thin red line is the fitted $\mathrm{H}_{2} \mathrm{CO}$ optical depth plus the residual, shown here to provide an idea of the fitting quality.

Typical values for the retrieved $\mathrm{H}_{2} \mathrm{CO}$ SCDs are in the range from $4 \times 10^{15}$ to $6 \times 10^{16}$ molecules $\mathrm{cm}^{-2}$. Fitting uncertainties for individual pixels range from $6 \times 10^{15}$ molecules $\mathrm{cm}^{-2}(\sim 30 \%)$ for pixels with high concentrations (above $2 \times 10^{16}$ molecules $\mathrm{cm}^{-2}$ ) to $100 \%$ or larger for pixels with low concentrations. These fitting uncertainties are calculated for the variable $j$ considering the diag- onal term of the covariance matrix for the fitting variable $C_{j, j}$ and the fitting residual weighted by the number of degrees of freedom (Eq. 2). Other sources of error in the fitting of the slant columns such as forward model errors or errors associated with parameters not optimized during the fitting are not considered in the calculation of the fitting uncertainties. Fitting rms values vary between $0.4 \times 10^{-3}$ and $2.0 \times 10^{-3}$, corresponding to detection limits between $\sim 6 \times 10^{15}$ and $\sim 3 \times 10^{16}$ molecules $\mathrm{cm}^{-2}$.

$\delta X_{j}^{2}=\operatorname{RMS}^{2}\left(\frac{m}{m-n}\right)\left(C_{(j, j)} C_{(j, j)}\right)$

\subsubsection{Vertical column density determination}

The second step of our retrieval converts SCDs into VCDs. The photons reaching OMI are either reflected from the Earth's surface and transmitted or scattered to OMI or directly scattered to OMI without reaching the Earth's surface. The retrieved SCDs depend on the viewing geometry for each pixel (solar zenith angle, viewing zenith angle, and relative azimuth angle), the surface albedo, and the state of the atmosphere (clouds, trace gases concentrations, temperature, air density, pressure, etc.). The SCDs are related to the VCDs by AMFs. The relationship between SCDs and VCDs is

$\mathrm{VCD}=\mathrm{SCD} / \mathrm{AMF}$

To determine AMFs, we follow the approach described in Palmer et al. (2001), summarized by Eq. (3).

$$
\begin{aligned}
& \mathrm{AMF}= \\
& \int_{\mathrm{atm}} w\left(z, \theta_{0}, \theta, \varphi, a_{s}, h_{s}, C_{f}, C_{h}\right) S(z, \text { lat, lon, month }) \mathrm{d} z
\end{aligned}
$$

In this formulation, the scattering weights ( $w$ 's) account for the sensitivity of the satellite measurements to the presence 
of $\mathrm{H}_{2} \mathrm{CO}$ molecules at different altitudes. They are functions of altitude $(z)$, solar zenith angle $\left(\theta_{0}\right)$, viewing zenith angle $(\theta)$, relative azimuth angle $(\varphi)$, surface albedo $\left(a_{\mathrm{S}}\right)$, terrain height $\left(h_{\mathrm{s}}\right)$, effective cloud fraction $\left(C_{\mathrm{f}}\right)$, and cloud-top altitude $\left(C_{\mathrm{h}}\right)$. For an optically thin absorber such as $\mathrm{H}_{2} \mathrm{CO}$, the $w$ 's are independent of the column abundance of the species. The shape factor $(S)$, dependent on the location and time of the measurement, represents the normalized vertical profile of the absorbing molecule and provides a priori estimation of the vertical distribution of $\mathrm{H}_{2} \mathrm{CO}$. The shape factor for a particular location and time is defined in Eq. (4).

$S(z)=\frac{x_{\mathrm{a}}(z)}{\int_{\mathrm{atm}} x_{\mathrm{a}}(z) \mathrm{d} z}$

$x_{\mathrm{a}}$ is the a priori vertical profile of $\mathrm{H}_{2} \mathrm{CO}$ partial columns. We have calculated vertical profiles using the GEOS-Chem (Bey et al., 2001) chemical transport model (Version v9-0103), which is driven by Goddard Earth Observing System-5 (GEOS-5)-assimilated meteorological data products interpolated onto 47 vertical levels at a spatial resolution of $2^{\circ}$ latitude $\times 2.5^{\circ}$ longitude. We have developed a monthly mean climatology using GEOS-Chem simulations between 13:00 and 14:00 local time (LT) in 2007. Figure 4 shows a set of vertical profiles used in the AMF calculation for Orbit 11118 at different latitudes.

We have calculated the scattering weights using the radiative transfer model VLIDORT version 2.4RT (Spurr, 2006). $w(z)$ usually depends on the wavelength and the viewing geometry. However, for solar zenith angles below $70^{\circ}$, since the ozone absorption is not too strong in the $328.5-356.5 \mathrm{~nm}$ fitting window, the variation of $w(z)$ with wavelength is small (less than $5 \%$ ). Therefore, we have used the scattering weights at only one optimized wavelength, $340 \mathrm{~nm}$. For solar zenith angles above $70^{\circ}$, the ozone absorption becomes large enough to make the assumption of an optically thin atmosphere not valid (we concentrate on SZA $<70^{\circ}$ ). We have prepared a set of weighting function look-up tables that are parameterized by the surface albedo and the relative azimuth angle, with entries for solar zenith angles (12), viewing zenith angles (8), altitudes (48), and cloud-top/surface pressures (6). These parameters are summarized in Table 2. OMCLDO2, the OMI cloud product we have used to obtain the cloud information (Acarreta et al., 2004), assumes the clouds to be opaque Lambertian surfaces at a single cloud height $\left(C_{\mathrm{h}}\right)$ with a cloud albedo $\left(a_{\mathrm{c}}\right)$ of $0.8-1.0$. At the retrieval partly cloudy pixels are assumed to be a mixture of clear-sky scene and cloudy scene $\left(a_{\mathrm{c}}=0.8\right)$ with an effective cloud fraction of $C_{\mathrm{f}}$ calculated using the independent pixel approximation (Martin et al., 2002). Under this approximation, the scattering weight for an inhomogeneous pixel with a given viewing geometry becomes

$w=(1-\Phi) \cdot w_{\text {clear }}\left(a_{\mathrm{s}}, h_{\mathrm{s}}\right)+\Phi \cdot w_{\text {cloud }}\left(a_{\mathrm{c}}, C_{\mathrm{h}}\right)$,

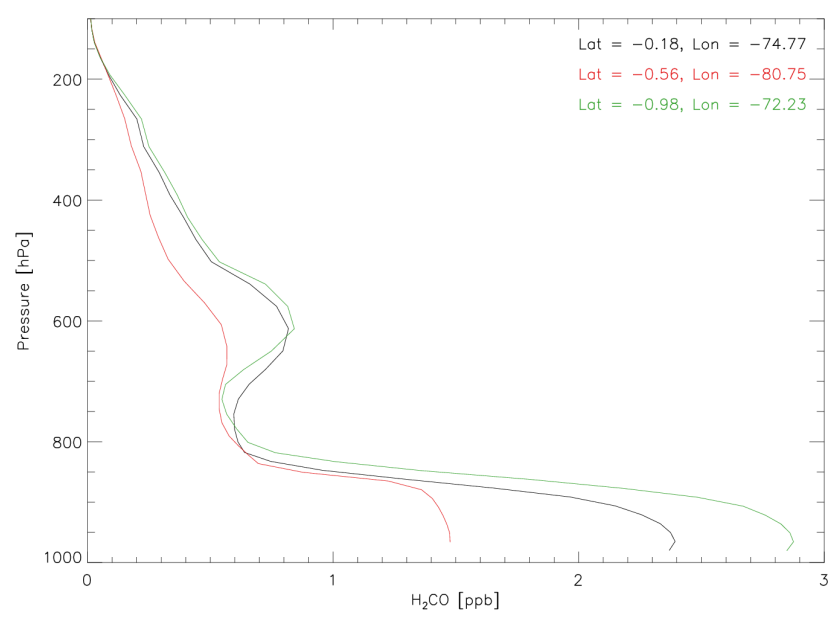

Figure 4. Three a priori $\mathrm{H}_{2} \mathrm{CO}$ profiles used in the air mass factor calculations for Orbit 11118.

where $w_{\text {clear }}$ is the scattering weight for the clear-sky part of the pixel, $a_{\mathrm{s}}$ is the surface albedo, $h_{\mathrm{s}}$ is the terrain height, $w_{\text {cloud }}$ is the scattering weight of the cloudy part of the pixel, $C_{\mathrm{h}}$ is the cloud height, and $\Phi$ is the intensity-weighted cloud fraction or radiative cloud fraction calculated as

$\Phi=\frac{C_{\mathrm{f}} \cdot I_{\text {cloud }}}{\left(1-C_{\mathrm{f}}\right) \cdot I_{\text {clear }}+C_{\mathrm{f}} \cdot I_{\text {cloud }}}$.

$I_{\text {clear }}$ and $I_{\text {cloud }}$ are the radiance intensities for clear-sky and cloudy scenes at the top of the atmosphere. The values of $I_{\text {clear }}$ and $I_{\text {cloud }}$ are calculated using VLIDORT and stored in a look-up table with the same parameter grid as the weighting function look-up table. The $a_{\mathrm{s}}$ used to evaluate $w_{\text {clear }}$ and $I_{\text {clear }}$ is obtained from the most frequent Lambertian equivalent reflectance (LER) field in version 3 of the OMI surface reflectance climatology (Kleipool et al., 2008). We calculate $a_{\mathrm{s}}$ by interpolating the values contained in the climatology to the wavelength where the AMFs are calculated, $340 \mathrm{~nm}$. For the terrain height, $h_{\mathrm{s}}$, we use the information provided with the OMI level 1B product (OML1BRUG). The description of clouds is consistent with the assumptions used in the cloud retrieval algorithm (Acarreta et al., 2004; Stammes et al., 2008) from which we obtain $C_{\mathrm{f}}$ and $C_{\mathrm{h}}$ distributed in the Aura OMI Cloud Data Product-OMCLDO2. Figure 5 shows the scattering weights for three pixels of Orbit 11118 with low, medium, and high effective cloud fractions. Once the scattering weights are calculated, the averaging kernels (AKs) (Rodgers and Connor, 2003) are straightforward to be approximated using the formulation shown below for DOAS retrievals (Eskes and Boersma, 2003):

$\mathrm{AK}(z)=\frac{w(z)}{\mathrm{AMF}}$.

$w_{z}$ is calculated as in Eq. (5), and AMFs are described by Eq. (3). Model comparisons with $\mathrm{H}_{2} \mathrm{CO}$ VCDs, assimilation of OMI $\mathrm{H}_{2} \mathrm{CO}$ products, and validation with $\mathrm{H}_{2} \mathrm{CO}$ profiles 
Table 2. Parameters of the weighting function look-up table.

\begin{tabular}{ll}
\hline Parameter & Grid values \\
\hline Solar zenith angle & $0,15,30,45,60,70,77,81,84,86,88,89\left[^{\circ}\right]$ \\
Viewing zenith angle & $0,15,30,45,60,70,75,80\left[^{\circ}\right]$ \\
Altitude & $0.06,0.19,0.32,0.45,0.59,0.73$, \\
& $0.86,1.00,1.15,1.29,1.44,1.58$, \\
& $1.76,1.99,2.25,2.52,2.79,3.08$, \\
& $3.44,3.90,4.38,4.88,5.42,5.98$, \\
& $6.59,7.24,7.95,8.86,9.96,11.04$, \\
& $12.11,13.15,14.19,15.22,16.24,17.26$, \\
& $18.81,20.93,23.12,25.42,29.16,34.65$, \\
& $40.93,48.04,55.86,64.16,74.49,80.79[\mathrm{~km}]$ \\
Cloud-top/surface pressure & $1.00,0.83,0.63,0.52,0.37,0.24[\mathrm{~atm}]$ \\
\hline
\end{tabular}

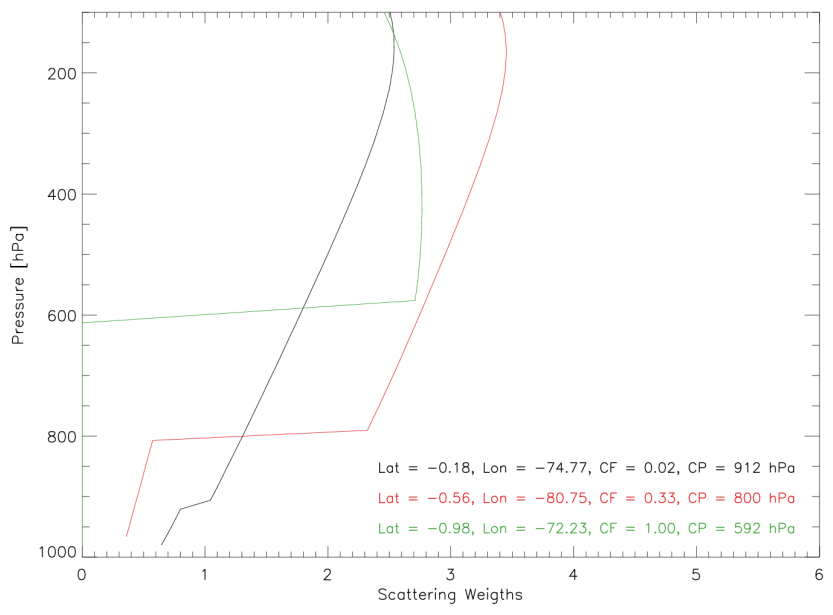

Figure 5. Example of calculated scattering weights for three pixels with different cloud fractions corresponding to the profiles plotted in Fig. 3. For cloud fractions equal to 1 the scattering weights below the cloud-top pressure become 0 (green line), while for other values there is a contribution below the cloud in the air mass factor calculation (red and black lines) proportional to the radiative cloud fraction.

should make use of the scattering weights and the used $\mathrm{H}_{2} \mathrm{CO}$ vertical profiles, so we provide them along with the columns.

We have performed a sensitivity analysis to assess the behavior of the AMFs calculations with respect to the $\mathrm{H}_{2} \mathrm{CO}$ vertical profile, the wavelength, the surface albedo, the viewing geometry, and the cloud parameters. We have defined a reference scenario for the AMF calculation considering a cloud-free pixel, with a surface albedo of 0.02 , a solar zenith angle of $30^{\circ}$, and a viewing zenith angle of $0^{\circ}$. The wavelength considered for the standard calculation is $340 \mathrm{~nm}$.

As mentioned above, the variation of the AMFs in function of the wavelength in the range of the fitting window is small, between 1 and $5 \%$. It is true and worth mentioning that at shorter wavelengths, below $330 \mathrm{~nm}$, the AMFs have a stronger dependency on the wavelength. This is one of the reasons to keep the lower limit of the fitting window on $328.5 \mathrm{~nm}$.

In the UV spectral range, most surfaces reflect between 1 and $10 \%$ of the incoming light. Kleipool et al. (2008) estimated the errors for the LER in the UV to be around $40 \%$. We can then estimate the errors we are carrying over from the albedo data into the AMF calculation for different surfaces. For example, the AMF of a typical surface with an albedo of 0.03 , such as a forest, will have a $6 \%$ error associated with the OMLER uncertainty. But for brighter surfaces, the error will be around $14 \%$ for the Sahara desert with an albedo of 0.1 and around $26 \%$ for a snow surface with an albedo of 0.8 . Therefore, we recommend the users to exercise caution when using retrievals over high albedo surfaces.

As mentioned before the dependence of the AMF in function of the SZA and VZA is strong. For example the AMF for our reference scenario can vary between 2 and 6 . Fortunately the geometries of the satellite observations are determined precisely and the errors associated to the inaccuracy of the viewing geometry are neglected.

The cloud pressure has an important impact in the value of the computed AMFs. Considering the reference scenario and a pixel fully covered with clouds the AMFs can range from 0.6 to 1.2 when the cloud pressure increases from 800 to $900 \mathrm{hPa}$. The cloud product we use is derived using the $\mathrm{O}_{2}-\mathrm{O}_{2}$ absorption band at $477 \mathrm{~nm}$ (Acarreta et al., 2004). An alternative to this product is the OMCLDRR cloud product, derived from rotational Raman scattering around $350 \mathrm{~nm}$ (Joiner and Vassilkov, 2006). The difference between these two data sets was estimated to be between 2 and $45 \mathrm{hPa}$ (Sneep et al., 2008). After propagating this difference in the cloud pressure to the calculations of the AMFs the values of the AMFs change around $20 \%$. The other cloud parameter we need to consider is the cloud fraction. Acarreta et al. (2004) estimated the systematic uncertainty of the cloud fraction to be \pm 0.1 . In the case of considering a cloud pressure of $800 \mathrm{hPa}$ a change in the cloud fraction of \pm 0.1 implies changes in the AMFs of around $25 \%$. 
We have also tested the impact of the a priori profiles of $\mathrm{H}_{2} \mathrm{CO}$. Assuming a bias in the GEOS-Chem profiles of $\pm 10 \%$ (Millet et al., 2006; Barkley et al., 2011) we have found that the AMF may change for different regions up to $16 \%$.

To summarize, the errors associated with AMF calculations are estimated to be around $35 \%$, dominated by the cloud parameters, the surface albedo, and the $\mathrm{H}_{2} \mathrm{CO}$ vertical profiles. The presence of aerosols in the atmosphere is an important factor, but we have not explicitly included them in our look-up tables to keep them consistent with the OMCLDO2 cloud product (Acarreta et al., 2004). The AMF uncertainties combined with the estimated errors on the SCDs (30-100\%) result in uncertainties associated with the VCDs between 45 and $105 \%$.

\subsubsection{Post-processing normalization of retrieved columns}

We derive a daily post-processing normalization for the retrieved columns according to the concentrations simulated by GEOS-Chem (Bey et al., 2001) over the remote Pacific, following an approach similar to Khokhar et al. (2005) and De Smedt et al. (2008). In this region, the $\mathrm{H}_{2} \mathrm{CO}$ concentrations are assumed to be at background levels, their only source being $\mathrm{CH}_{4}$ oxidation.

We define the reference sector as the region in-between 140 and $160^{\circ} \mathrm{W}$, and $90^{\circ} \mathrm{N}$ and $90^{\circ} \mathrm{S}$. Using $2.0^{\circ}$ latitude by $2.5^{\circ}$ longitude model results in 2007 , we have built a monthly mean climatology of VCDs by longitudinally averaging concentrations for a given latitude and then latitudinally interpolating the results to a grid of 500 points extending from $90^{\circ} \mathrm{N}$ to $90^{\circ} \mathrm{S}$ with a resolution of $0.36^{\circ}$. With these climatological values, taking into consideration the viewing geometry and atmospheric conditions of each pixel (i.e., AMF), we correct the effects of the row anomaly and stripping and normalize the retrieved values to the reference sector to remove the artificially increasing background $\mathrm{H}_{2} \mathrm{CO}$ values using the following approach.

We calculate a pixel-by-pixel correction (Eq. 8) over the remote Pacific Ocean (radiance reference granule) for the pixels whose SCD fitting has converged successfully above the noise level, and the retrieved SCD plus 2 times the fitting uncertainty are above 0 . These pixels are identified in the file product as good pixels by having a main data quality flag of 0 . Other possible values for the main quality flag are 1 for suspect pixels - with negative values for the retrieved column plus 2 times the fitting uncertainty but positive values for the column plus 3 times the fitting uncertainty, or with convergence of the fitting at the noise level - and value 2 for bad pixels, which are pixels where the fitting has not converged, or the retrieved values plus 3 times the fitting uncertainty remain below 0 .

$$
\begin{aligned}
& \operatorname{Correction}(i, j)=\mathrm{OMI}_{\mathrm{SCD} \_P a c i f i c}(i, j) \\
& -\left(\operatorname{GEOS} \_C h e m_{\text {ReferenceSector }}(\mathrm{lat}) \times \operatorname{AMF}(i, j)\right)
\end{aligned}
$$

$i$ is the a cross-track position (longitude) within an OMI orbit, $j$ is the line position (latitude), and lat is the latitude at the center of pixel $(i, j)$ of the orbit.

After working the pixel-by-pixel correction using the radiance reference orbit, we assume that the bias between the retrieved columns and the modeled columns over the remote Pacific Ocean (Correction $(i, j))$ is representative of a longitudinally invariant bias that affects the retrievals everywhere else on the globe. Therefore, we calculate a latitudedependent correction of this bias for each cross-track position using the median values of the corrections calculated in Eq. (8) falling within two points of the reference sector latitude grid. Finally we apply this bias to the rest of the orbits by interpolating the values of the median bias to the corresponding latitude at the center of each pixel.

We attribute this bias mainly to instrumental issues whose effects are weaker than the row anomaly, and to correlations between $\mathrm{BrO}$ and $\mathrm{H}_{2} \mathrm{CO}$ absorption cross sections, which are especially significant at high latitudes. One latitudedependent bias correction is calculated for each radiance reference orbit. In fact this implies that the bias correction is calculated daily. We consider this bias correction to be orbit invariant for all the retrievals performed with the same radiance reference (within $24 \mathrm{~h}$ difference). Therefore we apply it to all OMI columns retrieved from different granules over the globe (typically between 7 and 17 granules using a particular radiance reference). The final corrected columns are calculated as

$$
\operatorname{VCD}_{\text {corrected }}(i, j)=\frac{\operatorname{SCD}(i, j)-\operatorname{Correction}(i, j)}{\operatorname{AMF}(i, j)} .
$$

Figure 6 illustrates the GEOS-Chem results used in the calculation of the background levels for August 2007. Figure 7 shows the effect of the reference sector correction for the reference sector $\left(140\right.$ to $160^{\circ} \mathrm{W}$ and $90^{\circ} \mathrm{N}$ to $90^{\circ} \mathrm{S}$ ) for each month. We can see how at high latitudes in the winter months we consistently retrieve high values of $\mathrm{H}_{2} \mathrm{CO}$ when compared with the GEOS-Chem reference sector slant columns (left panels). It is therefore no surprise that the reference sector correction is strongest for the winter months in the high latitudes. We consider the month-to-month variation of the GEOS-Chem climatology to be representative of the changes in the background values, in comparison to the rapid spatial and temporal variation in concentrations over the continental hot spots.

Even though the correction helps us to remove unrealistic biases associated with the instrument and correlations between the $\mathrm{H}_{2} \mathrm{CO}$ and $\mathrm{BrO}$ cross sections, it introduces external a priori information subject to uncertainties and assumes that $\mathrm{H}_{2} \mathrm{CO}$ over the reference sector does not change from 


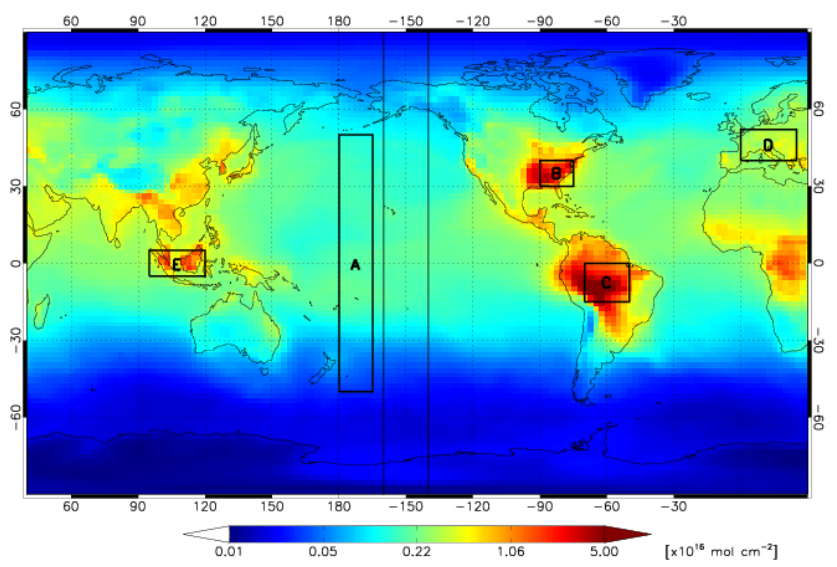

Figure 6. August 2007 GEOS-Chem monthly mean climatology used in the calculation of the reference sector background concentrations. The portion of the remote Pacific Ocean used is enclosed by the two black vertical lines. The region above Hawaii has been excluded from the longitudinally averaged concentrations. Note the logarithmic scale used for the colorbar. Overplotted are the five regions used in the time series shown in Fig. 9 as described in the text.

year to year. This situation should be considered when using the reference-sector-corrected columns. We provide in our data files both the reference-sector-corrected columns and the non-corrected VCDs so each user can develop a suitable reference sector correction.

\section{Comparison between previous and current $\mathrm{H}_{2} \mathrm{CO} S A O$ product}

We have changed the spectral fitting for the new version of the retrieval by updating some cross sections to newly available data, by considering the $\mathrm{O}_{2}-\mathrm{O}_{2}$ collision complex, and by changing the fitting window. Table 3 shows the mean SCD, mean fitting uncertainty, mean rms, and the percent of pixels flagged as good (main quality flag equal to 0) for OMI Orbit 11148 using different retrieval configurations. First we report the result from the old SAO retrieval and then the result after changing each one of the items listed below. The last line of Table 3 shows the results for the new retrieval. The mean SCD has changed from 7.52 to $11.02 \times 10^{15}$ molecules $\mathrm{cm}^{-2}$, the fitting uncertainty from 11 to $8.87 \times 10^{15}$ molecules $\mathrm{cm}^{-2}$, the rms from 1.31 to $1.22 \times 10^{-3}$, and the number of good pixels rises from 98.95 to $99.64 \%$.

The list of changes in the spectral fitting includes the highresolution solar spectrum from Chance and Spurr (1997) to Chance and Kurucz (2010), the $\mathrm{H}_{2} \mathrm{CO}$ cross sections from Cantrell et al. (1990) to Chance and Orphal (2011), and the use of two $\mathrm{O}_{3}$ cross sections at 228 and $295 \mathrm{~K}$ instead of only one at $228 \mathrm{~K}$ (Malicet et al., 1995). Another change is that we are fitting the $\mathrm{O}_{2}-\mathrm{O}_{2}$ collisional complex cross sec-
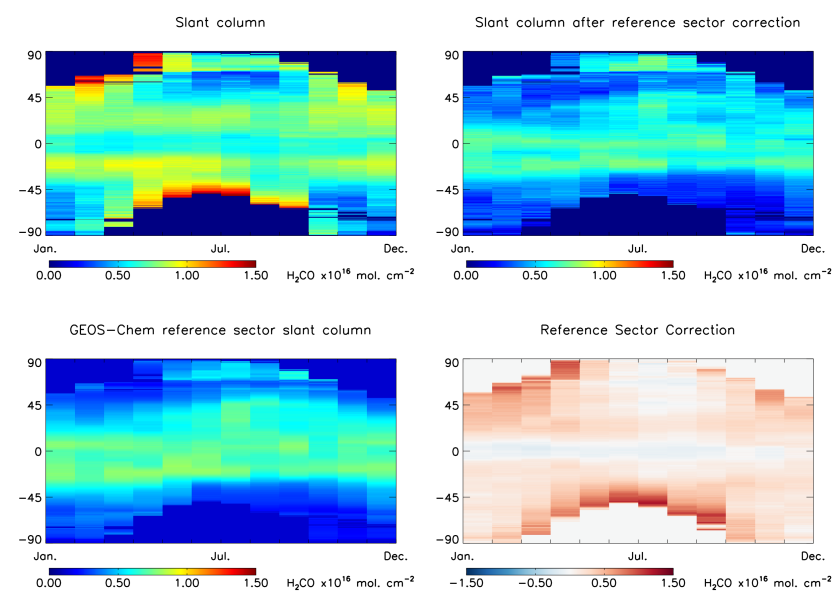

Figure 7. Analysis of the reference sector correction using monthly averages for the year 2007. Top left panel shows OMI-retrieved SCD for the reference sector $\left(140\right.$ to $\left.160^{\circ} \mathrm{W}\right)$, top right panel shows the OMI SCD after the reference sector correction is applied, bottom left panel the reference sector concentration from the GEOSChem climatology, and the bottom right panel the correction applied for each month and latitude bin.

tion (Thalman and Volkamer, 2013), while in the old SAO retrieval the $\mathrm{O}_{2}-\mathrm{O}_{2}$ collisional complex was not considered. The $\mathrm{O}_{2}-\mathrm{O}_{2}$ collisional complex has two significative features at 342 and $360 \mathrm{~nm}$ that are relevant in the $\mathrm{H}_{2} \mathrm{CO}$ fitting window. For that reason we consider it necessary to include it in the fitting. We have also modified the fitting window from $327.5-356.5 \mathrm{~nm}$ in the old SAO retrieval to $328.5-356.5 \mathrm{~nm}$ in the new retrieval.

To compare the long-term series of both retrievals, 3 years of data are used; years 2006 and 2007, near the beginning of the mission, are representative of a time when the previous SAO product is quite stable, while year 2012 is representative of a time when the previous SAO product is affected by problems, including the row anomaly and increasing background concentrations.

In general, the new product is less noisy, with smaller fitting uncertainties. This can be seen for the particular case of Orbit 43214 (August 2012) in Fig. 8. The decrease in uncertainty is evident with almost all pixels having an absolute uncertainty smaller than that in the older version of the SAO retrieval. There is also significant reduction of unrealistically high SCDs.

The general increase in the retrieved columns in the previous SAO retrieval is so large that it is difficult to use it after 2010 (Kim et al., 2011). In the new retrieval, the situation is greatly improved. In Fig. 9 (for Orbit 43214) we have plotted the retrieved VCDs for the old retrieval, the new one, and the new one with the reference sector correction applied to show how the situation has improved. The first panel, top left, gives VCDs retrieved with the old algorithm. Extremely high values (over $2.0 \times 10^{16}$ ) are common over the continents and 
Table 3. Spectral fitting results for Orbit 11118. Results from the old SAO retrieval and from different new retrieval settings are included to illustrate the change induced by each one of them.

\begin{tabular}{|c|c|c|c|c|}
\hline & $\begin{array}{l}\text { Mean SCD } \\
\text { molecules } \mathrm{cm}^{-2}\end{array}$ & $\begin{array}{l}\text { Mean uncertainty } \\
\text { molecules } \mathrm{cm}^{-2}\end{array}$ & Mean rms & $\%$ good pixels \\
\hline Old SAO & $7.52 \times 10^{15}$ & $1.10 \times 10^{16}$ & $1.31 \times 10^{-3}$ & 98.95 \\
\hline New fitting window & $8.41 \times 10^{15}$ & $1.03 \times 10^{16}$ & $1.31 \times 10^{-3}$ & 99.14 \\
\hline New solar reference & $5.56 \times 10^{15}$ & $1.02 \times 10^{16}$ & $1.34 \times 10^{-3}$ & 98.53 \\
\hline New $\mathrm{H}_{2} \mathrm{CO}$ cross sections & $4.48 \times 10^{15}$ & $9.14 \times 10^{15}$ & $1.33 \times 10^{-3}$ & 98.31 \\
\hline New $\mathrm{O}_{3}$ cross sections & $4.95 \times 10^{15}$ & $9.60 \times 10^{15}$ & $1.26 \times 10^{-3}$ & 97.67 \\
\hline $\mathrm{O}_{2}-\mathrm{O}_{2}$ cross sections & $7.03 \times 10^{15}$ & $9.85 \times 10^{15}$ & $1.29 \times 10^{-3}$ & 98.77 \\
\hline New SAO & $1.02 \times 10^{16}$ & $8.87 \times 10^{15}$ & $1.22 \times 10^{-3}$ & 99.64 \\
\hline
\end{tabular}

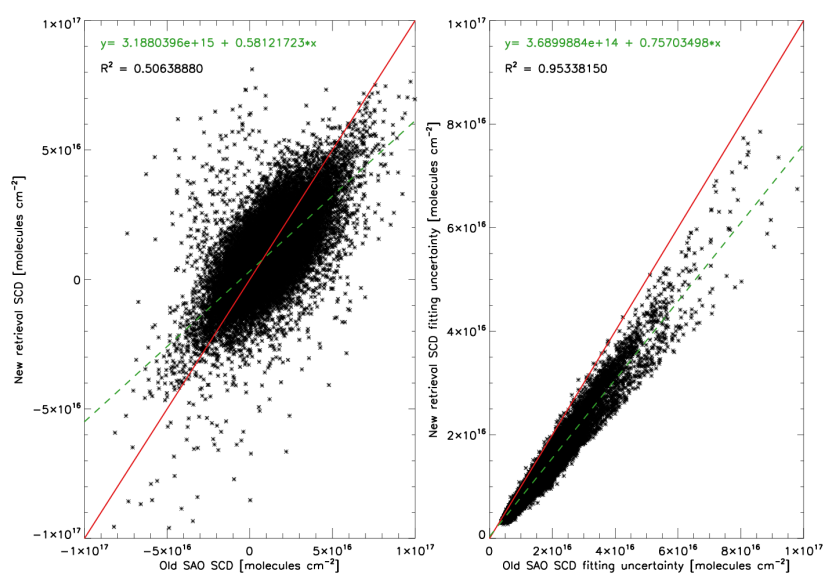

Figure 8. Scatterplots for Orbit 43214 comparing the old SAO retrieval and new SAO retrieval of SCDs and SCD fitting uncertainties.

equatorial ocean areas, while there are areas of negative values at high latitudes.

With the new algorithm without the reference sector correction, top right panel, it is evident that there is a significant reduction in the concentrations almost everywhere. The contrast between high- and low-concentration regions increases. The new retrieval also has fewer pixels with negative values at high latitudes. After we have applied the reference sector correction (bottom left panel), the situation further improves. As mentioned earlier, the new retrieval still shows large negative concentrations - which, however, are smaller in the new version - at high latitudes due to correlations with $\mathrm{BrO}$. Applying the reference sector correction helps to minimize this effect. Finally, we plot the difference between the VCDs retrieved with the old and the new products in the bottom right panel. The concentrations are reduced almost everywhere in the orbit (blue colors). We only see increases in concentrations where the old retrieval is consistently negative. There is also an improvement for pixels affected by the row anomaly in the new retrieval. However, we do not recommend using pixels affected by the row anomaly.

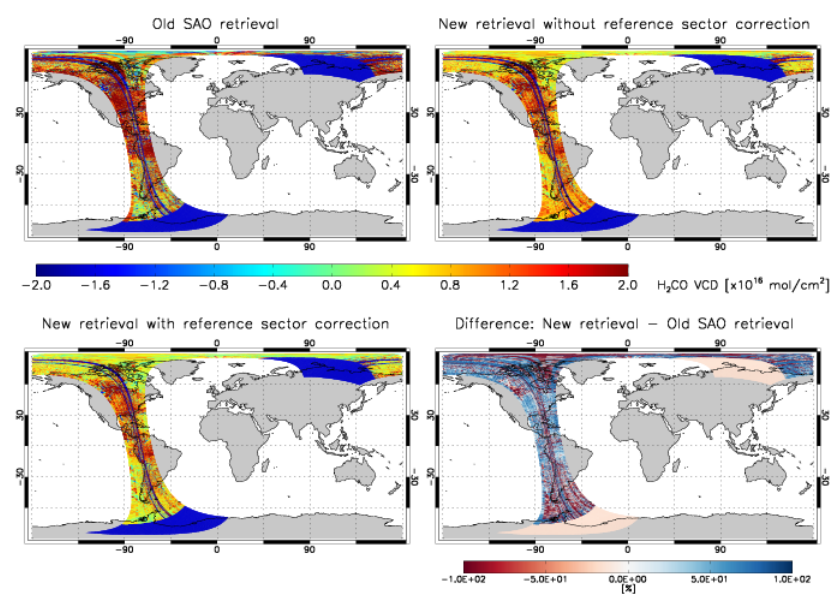

Figure 9. VCD retrieval for Orbit 43214, on 29 August 2012. The panels show the old SAO retrieval (top left), the new retrieval without reference sector correction applied to it (top right), the new retrieval with the reference sector correction applied (bottom left), and the difference between the new retrieval with the reference sector correction applied to it expressed as percent of the old operational retrieval (bottom right).

We now compare level 3 monthly averages to better assess changes in the concentrations and trends of the new retrieval with respect to the old SAO retrieval. To compute monthly averages, we only considered pixels with cloud fractions below $40 \%$ and unaffected by the row anomaly. The level 3 data are calculated on a $0.2^{\circ} \times 0.2^{\circ}$ grid where values of the OMI pixel are weighted by the area falling within the grid box and by the fitting uncertainty.

We have defined six regions in this study. Background levels over the remote Pacific Ocean (A), southeastern USA (B), the Amazon Basin (C), Europe (D), and southeast Asia (E) plus an equatorial Pacific Ocean area which includes only the latitudes between $-20^{\circ} \mathrm{S}$ and $20^{\circ} \mathrm{N}$ to assess the evolution of the SCD standard deviation in a remote area. The areas used for each of these regions are shown in Fig. 6. We have focused our analysis on 2006, 2007, and 2012. While the old SAO retrieval is stable until the end of 2007, by 2012 


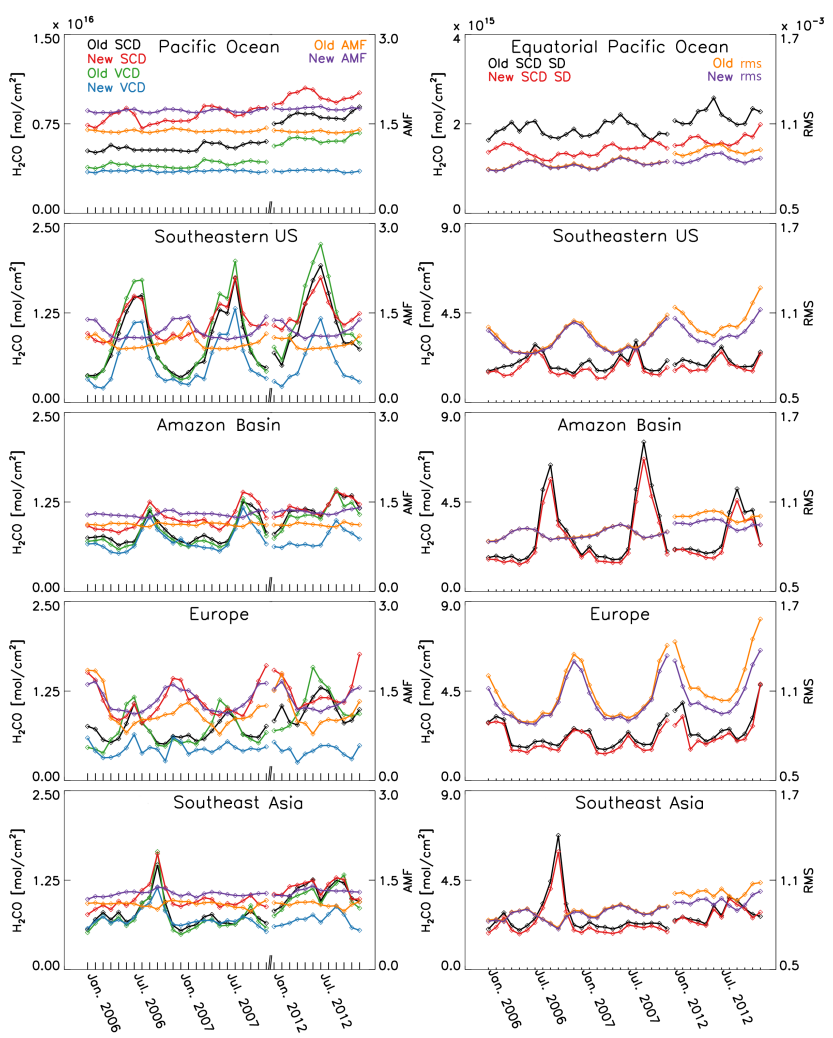

Figure 10. Year 2006, 2007, and 2012 monthly average of the $0.2^{\circ} \times 0.2^{\circ}$ gridded SCDs, VCDs (only reference sector corrected for the new retrieval), AMFs, rms's, and gridded SCD standard deviation time series for the regions depicted in Fig. 5 plus a sixth region named equatorial Pacific Ocean including the latitudes inside region $\mathrm{A}$ between $-20^{\circ} \mathrm{S}$ and $20^{\circ} \mathrm{N}$ added to study the evolution of the standard deviation of the gridded SCDs in a remote region. The break in the $x$ axis indicates the transition from 2007 to 2012 .

it is clearly producing unreasonable columns over the Pacific and an overall increase of the retrieved concentrations worldwide. The selected 3 years are thus appropriate for comparing the old and the new results.

Figure 10 shows the results of the time series comparison. Overall, the new retrieval (red and blue lines in the left panels) is more stable over time than the old retrieval (black and green lines in the left panels). The VCDs plotted for the new retrieval are the ones with the reference sector correction applied to them. In comparison with the old SAO retrieval the new one does not show a large increasing trend in the SCD or VCD concentrations. The background concentrations over the Pacific Ocean remain almost the same for the new retrieval, while the old SAO retrieval exhibits an increase of $0.3 \times 10^{16}$ molecules $\mathrm{cm}^{-2}$ between the end of 2007 and the beginning of 2012. However there is still some increase, albeit greatly reduced. We have not be able to attribute it to any specific cause after analyzing possible anisotropies introduced by the row anomaly in the viewing geometry of the pixels. What we can say is that we do not observe a degra-

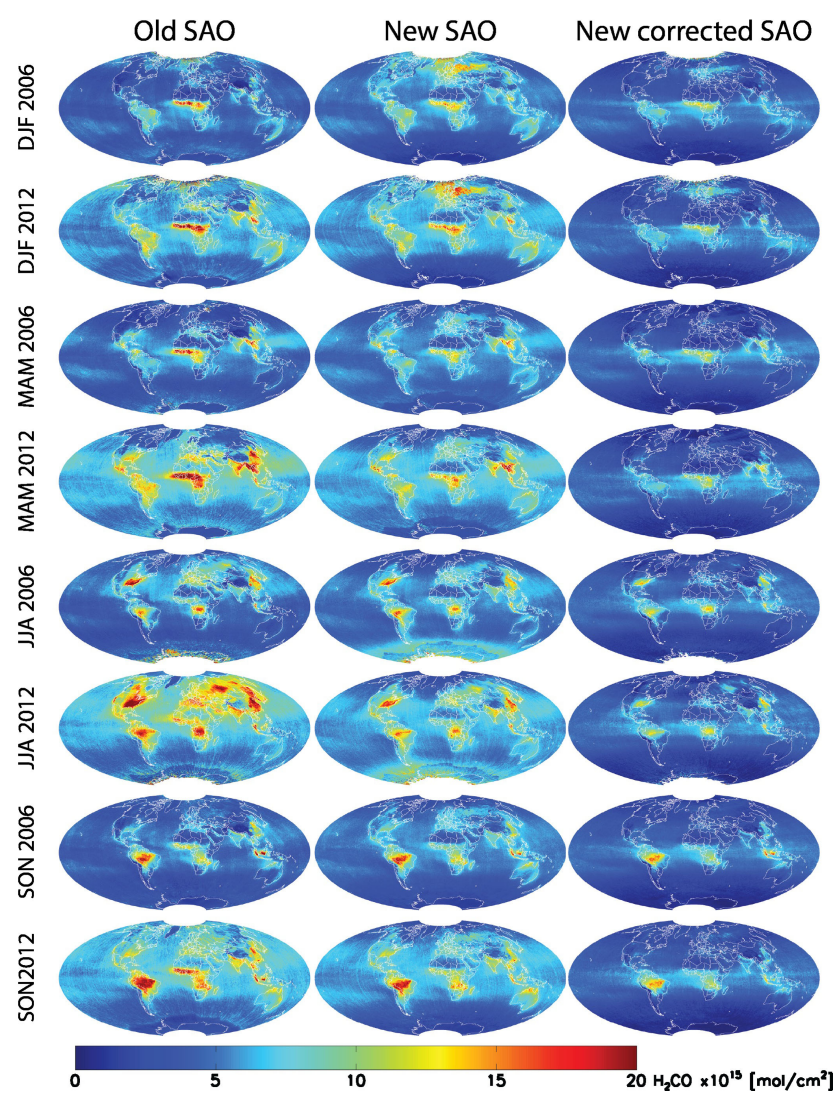

Figure 11. Seasonal averages for 2006 and 2012. Left column shows the old SAO retrieval, middle column shows the new retrieval without the reference sector correction, and right column shows new retrieval with the reference sector correction.

dation of the fitting residuals (orange and purple lines of the right side panels in Fig. 10) or increases in the standard deviations (black and red lines in the right side panels) in the new retrieval in opposition to what was observed in the old retrieval. The other regions have similar seasonality in the old and new retrievals, but the sharp increase in the background levels observed in the old retrieval from 2007 to 2012 is not present in the new retrieval, especially in the southeastern USA and southeast Asia. The retrieved columns in the new version do not show significant jumps between 2007 and 2012 for the rest of the regions analyzed. The main remaining issue in the new retrieval is the too-high winter concentrations over Europe. We recommend at present the values for December, January, and February over northern Europe to be used with caution.

In the left side panels of Fig. 10 we have also included the AMF for the old and new retrieval (orange and purple lines). As mentioned above, the use of the radiative cloud fraction instead of the effective cloud fraction translates to a general increase of the AMFs of around $20 \%$.

Figure 11 shows the results for the new retrieval without the reference sector correction applied in the middle panels, 


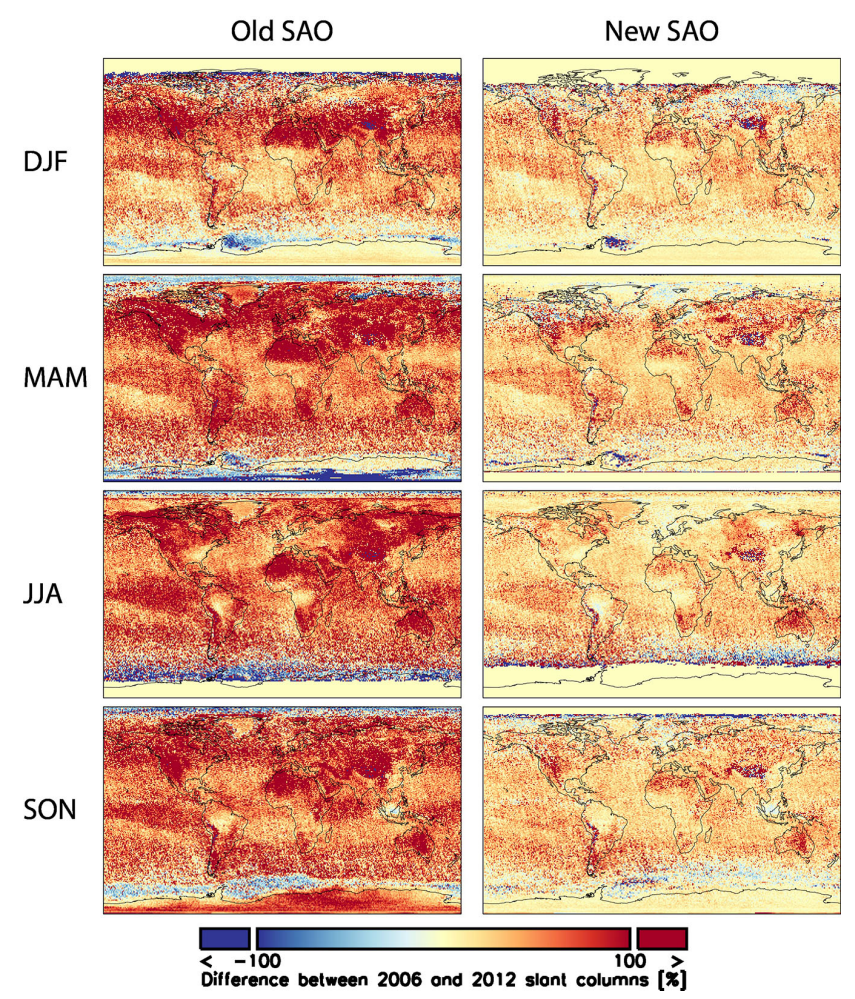

Figure 12. Difference between 2006 and 2012 slant column seasonal averages. Left column shows results for the old SAO retrieval, while the right column shows results for the new retrieval.

with the reference sector correction applied in the right panels, and the old SAO retrieval in the left panels. These plots are seasonal averages for DJF, MAM, JJA, and SON for the years 2006 and 2012. The reduction in the background values is evident in the new retrieval. Hot spots are more spatially resolved in the new retrieval, e.g., the hot spot over Central America in MAM. The high concentrations over the Mediterranean Sea in JJA are removed. To illustrate the reduction of the increasing trend in the new retrieval, Fig. 12 shows the difference of seasonally averaged slant columns between 2006 and 2012 (2012-2006) for the old (left column) and new (right column) retrievals. Apparently, the new retrieval has reduced the increasing trend significantly. The differences are well over $100 \%$ in the old version for most continental and oceanic regions in all seasons. While there is still an increasing trend in the new retrieval, it has been decreased to between 0 and $50 \%$ in most regions and seasons.

\section{Conclusions}

We have presented and discussed the new SAO OMI $\mathrm{H}_{2} \mathrm{CO}$ retrieval, paying especially attention to the changes with respect to the old operational algorithm. We have updated the $\mathrm{H}_{2} \mathrm{CO}$ cross sections and the high-resolution solar spectra. We have also included a second $\mathrm{O}_{3}$ cross sections at $295 \mathrm{~K}$ and the $\mathrm{O}_{2}-\mathrm{O}_{2}$ collisional complex. We have implemented an iterative fitting residual analysis to remove spectral pixels with high fitting residuals. We have slightly modified the fitting window and used a reference sector over the remote Pacific Ocean to correct for possible biases and their temporal drift in the retrieved slant columns. We have also updated the AMF calculation to include the radiative cloud fraction. This change has increased the value of the AMFs by $20 \%$ on average.

The columns retrieved by the new SAO OMI $\mathrm{H}_{2} \mathrm{CO}$ algorithm show more stability over time. The increasing trend in concentrations is greatly reduced, as is the increase in the rms and therefore the fitting uncertainties and the standard deviations of the columns. This new product greatly extends the volume of useful $\mathrm{H}_{2} \mathrm{CO}$ data from OMI beyond 2008 and also provides new data to facilitate its use. The scattering weights used in the SCD-to-VCD inversion and the associated $\mathrm{H}_{2} \mathrm{CO}$ vertical profiles are now included in the level 2 data files for use in model comparisons. We now include a quality flag in our product for problems caused by instrument row anomaly. As a general rule, we recommend users not to use pixels affected by the row anomaly.

The new operational algorithm will be version 3.2.0.3 in the algorithm development sequence. Generically we will refer to it as version 3. A detailed error analysis is in preparation. We are also working on further validation of our new product.

Acknowledgements. This study is supported by NASA Atmospheric Composition Program/Aura Science Team (NNX11AE58G) and the Smithsonian Institution. The DutchFinnish OMI instrument is part of the NASA EOS Aura satellite payload. The OMI project is managed by NIVR and KNMI in the Netherlands. We acknowledge the OMI International Science Team for providing OMI data used in this study.

Edited by: F. Boersma

\section{References}

Acarreta, J. R., De Haan, J. F., and Stammes, P.: Cloud pressure retrieval using the $\mathrm{O}_{2}-\mathrm{O}_{2}$ absorption band at $477 \mathrm{~nm}$, J. Geophys Res.-Atmos., 109, D05204, doi:10.1029/2003JD003915, 2004.

Anderson, L. G., Lanning, J. A., Barrell, R., Miyagishima, J., Jones, R. H., and Wolfe, P.: Sources and sinks of formaldehyde and acetaldehyde: An analysis of Denver's ambient concentration data, Atmos. Environ., 30, 2113-2123, doi:10.1016/13522310(95)00175-1, 1996.

Barkley, M. P., Palmer, P. I., Kuhn, U., Kesselmeier, J., Chance, K., Kurosu, T. P., Martin, R. V., Helmig, D., and Guenther, A.: Net ecosystem fluxes of isoprene over tropical South America inferred from Global Ozone Monitoring Experiment (GOME) observations of HCHO columns, J. Geophys. Res.-Atmos., 113, D20304, doi:10.1029/2008JD009863, 2008. 
Barkley, M. P., Palmer, P. I., Ganzeveld, L., Arneth, A., Hagberg, D., Karl, T., Guenther, A., Paulot, F., Wennberg, P. O., Mao, J., Kurosu, T. P., Chance, K., Müller, J.-F., De Smedt, I., Van Roozendael, M., Chen, D., Wang, Y., and Yantosca, R. M.: Can a "state of the art" chemistry transport model simulate Amazonian tropospheric chemistry?, J. Geophys. Res.-Atmos., 116, D16302, doi:10.1029/2011JD015893, 2011.

Bey, I., Jacob, D. J., Yantosca, R. M., Logan, J. A., Field, B. D., Fiore, A. M., Li, Q., Liu, H. Y., Mickley, L. J., and Schultz, M. G.: Global modeling of tropospheric chemistry with assimilated meteorology: Model description and evaluation, J. Geophys. Res.-Atmos., 106, 23073-23095, doi:10.1029/2001JD000807, 2001.

Brune, W. H., Tan, D., Faloona, I. F., Jaeglé, L., Jacob, D. J., Heikes, B. G., Snow, J., Kondo, Y., Shetter, R., Sachse, G. W., Anderson, B., Gregory, G. L., Vay, S., Singh, H. B., Davis, D. D., Crawford, J. H., and Blake, D. R.: $\mathrm{OH}$ and $\mathrm{HO}_{2}$ chemistry in the North Atlantic free troposphere, Geophys. Res. Lett., 26, 3077-3080, doi:10.1029/1999GL900549, 1999.

Cantrell, C. A., Davidson, J. A., McDaniel, A. H., Shetter, R. E., and Calvert, J. G.: Temperature-dependent formaldehyde cross sections in the near-ultraviolet spectral region, J. Phys. Chem., 94, 3902-3908, doi:10.1021/j100373a008, 1990.

Caspar, C. and Chance, K.: GOME wavelength calibration using solar and atmospheric spectra, in: Third ERS Symposium on Space at the service of our Environment, edited by: Guyenne, T.-D. and Danesy, D., Vol. 414 of ESA Special Publication, p. 609, 1997.

Chance, K.: Analysis of BrO measurements from the Global Ozone Monitoring Experiment, Geophys. Res. Lett., 25, 3335-3338, doi:10.1029/98GL52359, 1998.

Chance, K. and Kurucz, R.: An improved high-resolution solar reference spectrum for earth's atmosphere measurements in the ultraviolet, visible, and near infrared, J. Quant. Spectrosc. Ra., 111, 1289-1295, doi:10.1016/j.jqsrt.2010.01.036, 2010.

Chance, K. and Orphal, J.: Revised ultraviolet absorption cross sections of $\mathrm{H}_{2} \mathrm{CO}$ for the HITRAN database, J. Quant. Spectrosc. Ra., 112, 1509-1510, doi:10.1016/j.jqsrt.2011.02.002, 2011.

Chance, K., Palmer, P. I., Spurr, R. J. D., Martin, R. V., Kurosu, T. P., and Jacob, D. J.: Satellite observations of formaldehyde over North America from GOME, Geophys. Res. Lett., 27, 34613464, doi:10.1029/2000GL011857, 2000.

Chance, K., Kurosu, T. P., and Sioris, C. E.: Undersampling correction for array detector-based satellite spectrometers, Appl. Optics, 44, 1296-1304, doi:10.1364/AO.44.001296, 2005.

Chance, K. V. and Spurr, R. J. D.: Ring effect studies: Rayleigh scattering, including molecular parameters for rotational Raman scattering, and the Fraunhofer spectrum, Appl. Optics, 36, 52245230, doi:10.1364/AO.36.005224, 1997.

De Smedt, I., Müller, J.-F., Stavrakou, T., van der A, R., Eskes, H., and Van Roozendael, M.: Twelve years of global observations of formaldehyde in the troposphere using GOME and SCIAMACHY sensors, Atmos. Chem. Phys., 8, 4947-4963, doi:10.5194/acp-8-4947-2008, 2008.

De Smedt, I., Van Roozendael, M., Stavrakou, T., Müller, J.-F., Lerot, C., Theys, N., Valks, P., Hao, N., and van der A, R.: Improved retrieval of global tropospheric formaldehyde columns from GOME-2/MetOp-A addressing noise reduction and instrumental degradation issues, Atmos. Meas. Tech., 5, 2933-2949, doi:10.5194/amt-5-2933-2012, 2012.
Dirksen, R., Dobber, M., Voors, R., and Levelt, P.: Prelaunch characterization of the Ozone Monitoring Instrument transfer function in the spectral domain, Appl. Optics, 45, 3972-3981, doi:10.1364/AO.45.003972, 2006.

Dufour, G., Szopa, S., Barkley, M. P., Boone, C. D., Perrin, A., Palmer, P. I., and Bernath, P. F.: Global uppertropospheric formaldehyde: seasonal cycles observed by the ACE-FTS satellite instrument, Atmos. Chem. Phys., 9, 38933910, doi:10.5194/acp-9-3893-2009, 2009.

Eskes, H. J. and Boersma, K. F.: Averaging kernels for DOAS totalcolumn satellite retrievals, Atmos. Chem. Phys., 3, 1285-1291, doi:10.5194/acp-3-1285-2003, 2003.

Fu, T.-M., Jacob, D. J., Palmer, P. I., Chance, K., Wang, Y. X., Barletta, B., Blake, D. R., Stanton, J. C., and Pilling, M. J.: Spacebased formaldehyde measurements as constraints on volatile organic compound emissions in east and south Asia and implications for ozone, J. Geophys. Res-Atmos., 112, D06312, doi:10.1029/2006JD007853, 2007.

Heckel, A., Richter, A., Tarsu, T., Wittrock, F., Hak, C., Pundt, I., Junkermann, W., and Burrows, J. P.: MAX-DOAS measurements of formaldehyde in the Po-Valley, Atmos. Chem. Phys., 5, 909918, doi:10.5194/acp-5-909-2005, 2005.

Houweling, S., Dentener, F., and Lelieveld, J.: The impact of nonmethane hydrocarbon compounds on tropospheric photochemistry, J. Geophys. Res.-Atmos., 103, 10673-10696, doi:10.1029/97JD03582, 1998.

Joiner, J. and Vassilkov, A. P.: First results from the OMI rotational Raman scattering cloud pressure algorithm, IEEE T. Geosci. Remote Sens., 44, 1272-1282, doi:10.1109/TGRS.2005.861385, 2006.

Jones, N. B., Riedel, K., Allan, W., Wood, S., Palmer, P. I., Chance, K., and Notholt, J.: Long-term tropospheric formaldehyde concentrations deduced from ground-based fourier transform solar infrared measurements, Atmos. Chem. Phys., 9, 7131-7142, doi:10.5194/acp-9-7131-2009, 2009.

Kanakidou, M., Seinfeld, J. H., Pandis, S. N., Barnes, I., Dentener, F. J., Facchini, M. C., Van Dingenen, R., Ervens, B., Nenes, A., Nielsen, C. J., Swietlicki, E., Putaud, J. P., Balkanski, Y., Fuzzi, S., Horth, J., Moortgat, G. K., Winterhalter, R., Myhre, C. E. L., Tsigaridis, K., Vignati, E., Stephanou, E. G., and Wilson, J.: Organic aerosol and global climate modelling: a review, Atmos. Chem. Phys., 5, 1053-1123, doi:10.5194/acp-5-1053-2005, 2005.

Khokhar, M., Frankenberg, C., Roozendael, M. V., Beirle, S., Kuhl, S., Richter, A., Platt, U., and Wagner, T.: Satellite observations of atmospheric $\mathrm{SO}_{2}$ from volcanic eruptions during the time-period of 19962002, Adv. Space Res., 36, 879-887, 2005.

Kim, J. H., Kim, S. M., Baek, K. H., Wang, L., Kurosu, T., De Smedt, I., Chance, K., and Newchurch, M. J.: Evaluation of satellite-derived HCHO using statistical methods, Atmos. Chem. Phys. Discuss., 11, 8003-8025, doi:10.5194/acpd11-8003-2011, 2011.

Kleipool, Q. L., Dobber, M. R., de Haan, J. F., and Levelt, P. F.: Earth surface reflectance climatology from 3 years of OMI data, J. Geophys. Res.-Atmos., 113, D18308, doi:10.1029/2008JD010290, 2008.

Kurosu, T. P., Chance, K., and Sioris, C. E.: Preliminary results for $\mathrm{HCHO}$ and $\mathrm{BrO}$ from the EOS-Aura Ozone Monitoring Instrument, Proc. SPIE, 5652, 116-123, doi:10.1117/12.578606, 2004. 
Levelt, P. F., van den Oord, G. H. J., Dobber, M. R., Mälkki, A., Visser, H., de Vries, J., Stammes, P., Lundell, J. O. V., and Saari, H.: The ozone monitoring instrument, IEEE T. Geosci. Remote., 44, 1093-1101, 2006.

Lindström, P. and Wedin, P.-A.: Methods and software for nonlinear least squares problems, Technical report UMINF-133.87, Inst. of Information Processing, University of Umeå, Umeå, Sweden, 1988.

Lowe, D. C. and Schmidt, U.: Formaldehyde (HCHO) measurements in the nonurban atmosphere, J. Geosphys. Res.-Oceans, 88, 10844-10858, doi:10.1029/JC088iC15p10844, 1983.

Malicet, J., Daumont, D., Charbonnier, J., Parisse, C., Chakir, A., and Brion, J.: Ozone UV spectroscopy. II. Absorption crosssections and temperature dependence, J. Atmos. Chem., 21, 263 273, doi:10.1007/BF00696758, 1995.

Marais, E. A., Jacob, D. J., Kurosu, T. P., Chance, K., Murphy, J. G., Reeves, C., Mills, G., Casadio, S., Millet, D. B., Barkley, M. P., Paulot, F., and Mao, J.: Isoprene emissions in Africa inferred from OMI observations of formaldehyde columns, Atmos. Chem. Phys., 12, 6219-6235, doi:10.5194/acp-12-62192012, 2012.

Martin, R. V., Chance, K., Jacob, D. J., Kurosu, T. P., Spurr, R. J. D., Bucsela, E., Gleason, J. F., Palmer, P. I., Bey, I., Fiore, A. M., Li, Q., Yantosca, R. M., and Koelemeijer, R. B. A.: An improved retrieval of tropospheric nitrogen dioxide from GOME, J. Geophys. Res.-Atmos., 107, ACH9.1-ACH9.21, doi:10.1029/2001JD001027, 2002.

Miller, C. C., Abad, G. G., Wang, H., Liu, X., Kurosu, T., Jacob, D. J., and Chance, K.: Glyoxal retrieval from the Ozone Monitoring Instrument, Atmos. Meas. Tech. Discuss., 7, 6065-6112, doi:10.5194/amtd-7-6065-2014, 2014.

Millet, D. B., Jacob, D. J., Turquety, S., Hudman, R. C., Wu, S., Fried, A., Walega, J., Heikes, B. G., Blake, D. R., Singh, H. B., Anderson, B. E., and Clarke, A. D.: Formaldehyde distribution over North America: Implications for satellite retrievals of formaldehyde columns and isoprene emission, J. Geophys. Res.Atmos., 111, D24S02, doi:10.1029/2005JD006853, 2006.

Palmer, P. I., Jacob, D. J., Chance, K., Martin, R. V., Spurr, R. J. D., Kurosu, T. P., Bey, I., Yantosca, R., Fiore, A., and Li, Q.: Air mass factor formulation for spectroscopic measurements from satellites: Application to formaldehyde retrievals from the Global Ozone Monitoring Experiment, J. Geophys. Res.-Atmos., 106, 14539-14550, doi:10.1029/2000JD900772, 2001.

Parrish, D. D., Ryerson, T. B., Mellqvist, J., Johansson, J., Fried, A., Richter, D., Walega, J. G., Washenfelder, R. A., de Gouw, J. A., Peischl, J., Aikin, K. C., McKeen, S. A., Frost, G. J., Fehsenfeld, F. C., and Herndon, S. C.: Primary and secondary sources of formaldehyde in urban atmospheres: Houston Texas region, Atmos. Chem. Phys., 12, 3273-3288, doi:10.5194/acp-12-32732012, 2012.

Peters, E., Wittrock, F., Großmann, K., Frieß, U., Richter, A., and Burrows, J. P.: Formaldehyde and nitrogen dioxide over the remote western Pacific Ocean: SCIAMACHY and GOME-2 validation using ship-based MAX-DOAS observations, Atmos. Chem. Phys., 12, 11179-11197, doi:10.5194/acp-12-111792012, 2012.

Pinardi, G., Van Roozendael, M., Abuhassan, N., Adams, C., Cede, A., Clémer, K., Fayt, C., Frieß, U., Gil, M., Herman, J., Hermans, C., Hendrick, F., Irie, H., Merlaud, A., Navarro Comas, M.,
Peters, E., Piters, A. J. M., Puentedura, O., Richter, A., Schönhardt, A., Shaiganfar, R., Spinei, E., Strong, K., Takashima, H., Vrekoussis, M., Wagner, T., Wittrock, F., and Yilmaz, S.: MAXDOAS formaldehyde slant column measurements during CINDI: intercomparison and analysis improvement, Atmos. Meas. Tech., 6, 167-185, doi:10.5194/amt-6-167-2013, 2013.

Richter, A., Begoin, M., Hilboll, A., and Burrows, J. P.: An improved $\mathrm{NO}_{2}$ retrieval for the GOME-2 satellite instrument, Atmos. Meas. Tech., 4, 1147-1159, doi:10.5194/amt-4-1147-2011, 2011.

Rodgers, C. D. and Connor, B. J.: Intercomparison of remote sounding instruments, J. Geophys. Res.-Atmos., 108, 4116, doi:10.1029/2002JD002299, 2003.

Sneep, M., de Haan, J. F., Stammes, P., Wang, P., Vanbauce, C., Joiner, J., Vasilkov, A. P., and Levelt, P. F.: Three-way comparison between OMI and PARASOL cloud pressure products, J. Geophys. Res.-Atmos., 113, doi:10.1029/2007JD008694, 2008.

Spurr, R. J.: VLIDORT: A linearized pseudo-spherical vector discrete ordinate radiative transfer code for forward model and retrieval studies in multilayer multiple scattering media, J. Quant. Spectrosc. Ra., 102, 316-342, 2006.

Stammes, P., Sneep, M., de Haan, J. F., Veefkind, J. P., Wang, P., and Levelt, P. F.: Effective cloud fractions from the Ozone Monitoring Instrument: Theoretical framework and validation, J. Geophys. Res.-Atmos., 113, D16S38, doi:10.1029/2007JD008820, 2008.

Stavrakou, T., Müller, J.-F., De Smedt, I., Van Roozendael, M., van der Werf, G. R., Giglio, L., and Guenther, A.: Evaluating the performance of pyrogenic and biogenic emission inventories against one decade of space-based formaldehyde columns, Atmos. Chem. Phys., 9, 1037-1060, doi:10.5194/acp-9-1037-2009, 2009a.

Stavrakou, T., Müller, J.-F., De Smedt, I., Van Roozendael, M., van der Werf, G. R., Giglio, L., and Guenther, A.: Global emissions of non-methane hydrocarbons deduced from SCIAMACHY formaldehyde columns through 2003-2006, Atmos. Chem. Phys., 9, 3663-3679, doi:10.5194/acp-9-3663-2009, $2009 \mathrm{~b}$.

Steck, T., Glatthor, N., von Clarmann, T., Fischer, H., Flaud, J. M., Funke, B., Grabowski, U., Höpfner, M., Kellmann, S., Linden, A., Perrin, A., and Stiller, G. P.: Retrieval of global upper tropospheric and stratospheric formaldehyde $\left(\mathrm{H}_{2} \mathrm{CO}\right)$ distributions from high-resolution MIPAS-Envisat spectra, Atmos. Chem. Phys., 8, 463-470, doi:10.5194/acp-8-463-2008, 2008.

Thalman, R. and Volkamer, R.: Temperature dependent absorption cross-sections of $\mathrm{O}_{2}-\mathrm{O}_{2}$ collision pairs between 340 and $630 \mathrm{~nm}$ and at atmospherically relevant pressure, Phys. Chem. Chem. Phys., 15, 15371-15381, doi:10.1039/C3CP50968K, 2013.

Vandaele, A., Hermans, C., Simon, P., Carleer, M., Colin, R., Fally, S., Mérienne, M., Jenouvrier, A., and Coquart, B.: Measurements of the $\mathrm{NO}_{2}$ absorption cross-section from $42000 \mathrm{~cm}^{-1}$ to $10000 \mathrm{~cm}^{-1}(238-1000 \mathrm{~nm})$ at $220 \mathrm{~K}$ and $294 \mathrm{~K}$, J. Quant. Spectrosc. Ra., 59, 171-184, 1998.

Veihelmann, B. and Kleipool, Q.: Reducing AlongTrack Stripes in OMI-Level 2 Products, Technical report TN-OMIE-KNMI-785, KNMI, available at: http: //disc.sci.gsfc.nasa.gov/Aura/data-holdings/OMI/documents/ v003/RD08_TN785_i1_Reducing_AlongTrack_Stripes.pdf (last access: 13 March 2006), 2006. 
Vigouroux, C., Hendrick, F., Stavrakou, T., Dils, B., De Smedt, I., Hermans, C., Merlaud, A., Scolas, F., Senten, C., Vanhaelewyn, G., Fally, S., Carleer, M., Metzger, J.-M., Müller, J.-F., Van Roozendael, M., and De MaziÈre, M.: Ground-based FTIR and MAX-DOAS observations of formaldehyde at Réunion Island and comparisons with satellite and model data, Atmos. Chem. Phys., 9, 9523-9544, doi:10.5194/acp-9-9523-2009, 2009.

Vrekoussis, M., Wittrock, F., Richter, A., and Burrows, J. P.: GOME-2 observations of oxygenated VOCs: what can we learn from the ratio glyoxal to formaldehyde on a global scale?, Atmos. Chem. Phys., 10, 10145-10160, doi:10.5194/acp-1010145-2010, 2010.

Wagner, T., Beirle, S., Brauers, T., Deutschmann, T., Frieß, U., Hak, C., Halla, J. D., Heue, K. P., Junkermann, W., Li, X., Platt, U., and Pundt-Gruber, I.: Inversion of tropospheric profiles of aerosol extinction and $\mathrm{HCHO}$ and $\mathrm{NO}_{2}$ mixing ratios from MAX-DOAS observations in Milano during the summer of 2003 and comparison with independent data sets, Atmos. Meas. Tech., 4, 2685-2715, doi:10.5194/amt-4-2685-2011, 2011.
Wang, H., Liu, X., Chance, K., Gonzalez Abad, G., and Chan Miller, C.: Water vapor retrieval from OMI visible spectra, Atmos. Meas. Tech., 7, 1901-1913, 2014, http://www.atmos-meas-tech.net/7/1901/2014/.

Wilmouth, D. M., Hanisco, T. F., Donahue, N. M., and Anderson, J. G.: Fourier Transform Ultraviolet Spectroscopy of the A $2 \Pi 3 / 2 \leftarrow \mathrm{X} 2 \Pi 3 / 2$ Transition of BrO $\dagger$, J. Phys. Chem. A, 103, 8935-8945, doi:10.1021/jp991651o, 1999.

Wittrock, F., Richter, A., Oetjen, H., Burrows, J. P., Kanakidou, M., Myriokefalitakis, S., Volkamer, R., Beirle, S., Platt, U., and Wagner, T.: Simultaneous global observations of glyoxal and formaldehyde from space, Geophys. Res. Lett., 33, L16804, doi:10.1029/2006GL026310, 2006. 